\title{
Follow-up investigation of antibody titers and diagnostic antibody cutoff values in patients with scrub typhus in South Korea
}

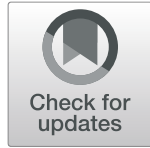

\author{
Choon-Mee Kim', Dong-Min Kim² ${ }^{2 *}$ and Na Ra Yun²
}

\begin{abstract}
Background: Scrub typhus is a mite-borne infectious disease caused by Orientia tsutsugamushi. Few follow-up studies have assessed antibody titers using serologic tests from various commercial laboratories and the Korea Centers for Disease Control and Prevention (KCDC).

Methods: A prospective study to assess the antibody titers in patients with scrub typhus and seroprevalence in individuals undergoing health checkups was conducted using results of immunofluorescence antibody assays (IFAs) and serologic tests, used by the KCDC and commercial laboratories, respectively. The following tests were performed simultaneously: (i) indirect IFA used by the KCDC to detect immunoglobulin (Ig) M and IgG, (ii) IFA used by a commercial laboratory to detect total Ig, and (iii) antibody tests using two commercially available kits.

Results: When the IgM and IgG cutoff values ( $\geq 1: 16$ and $\geq 1: 256$, respectively) used in the IFA and the total IgG cutoff values ( $\geq 1: 40$ ) were used in prospective follow-up investigations, the antibody positivity rates of 102 patients with scrub typhus were 44.1, 35.3, and 57.6\%, respectively, within 5 days of symptom onset. Among 91 individuals who recovered from scrub typhus, the follow-up IgM, IgG, and total Ig positivity rates for 13 years were 37.4\% (34/ 91), 22.0\% (20/91), and 76.9\% (70/91), respectively. Among 216 individuals undergoing health checkups, the seroprevalence of IgM was 4.2\% (9/216); no seroprevalence of IgG was observed.

Conclusions: IFAs used by the KCDC and the commercial laboratory and rapid commercial kits could not distinguish between patients who had recovered from scrub typhus and those who are currently infected with $O$. tsutsugamushi. In South Korea and other countries, where low antibody cutoff values are used, upward adjustments of cutoff values may be necessary.
\end{abstract}

Keywords: Scrub typhus, Fluorescent antibody technique, Orientia tsutsugamushi

\footnotetext{
* Correspondence: drongkim@chosun.ac.kr

${ }^{2}$ Departments of Internal Medicine, College of Medicine, Chosun University, Gwangju, Republic of Korea

Full list of author information is available at the end of the article
}

(c) The Author(s). 2021 Open Access This article is licensed under a Creative Commons Attribution 4.0 International License, which permits use, sharing, adaptation, distribution and reproduction in any medium or format, as long as you give appropriate credit to the original author(s) and the source, provide a link to the Creative Commons licence, and indicate if changes were made. The images or other third party material in this article are included in the article's Creative Commons licence, unless indicated otherwise in a credit line to the material. If material is not included in the article's Creative Commons licence and your intended use is not permitted by statutory regulation or exceeds the permitted use, you will need to obtain permission directly from the copyright holder. To view a copy of this licence, visit http://creativecommons.org/licenses/by/4.0/ The Creative Commons Public Domain Dedication waiver (http://creativecommons.org/publicdomain/zero/1.0/) applies to the data made available in this article, unless otherwise stated in a credit line to the data. 


\section{Background}

Scrub typhus is a vector-borne infectious disease caused by Orientia tsutsugamushi, which is transmitted by a chigger bite [1]. The most common method of diagnosing scrub typhus is serological tests; indirect immunofluorescence antibody assays (IFA), enzyme-linked immunosorbent assays, and passive hemagglutination assays are used to detect the presence of antibodies (Abs) against $O$. tsutsugamushi. However, these tests have limited clinical usefulness because antibodies are usually formed 1-2 weeks after infection [2]. The gold standard diagnostic method is based on a $\geq 4$-fold increase in $\mathrm{Ab}$ titer; however, the possibility of false-positive results cannot be excluded in cases with a 4-fold increase from a low titer [3]. Moreover, it is clinically difficult to perform follow-up investigations to check Ab titers. Even if Ab titers are monitored, a $\geq 4$-fold increase may not be observed in cases with high early titers. In a previous study, a $\geq 4$-fold increase in immunoglobulin (Ig) $\mathrm{M}$ and IgG levels were observed in only 61 and $72 \%$ cases, respectively, $\geq 1$ month after symptom onset [4]. Hence, many countries use cutoff values to diagnose scrub typhus.

To identify an appropriate cutoff value of $\mathrm{Ab}$ titer in diagnostic serologic tests for scrub typhus, it is necessary to examine the titer levels and the duration for which these levels are sustained in patients who have recovered from scrub typhus. However, follow-up studies to examine titers in patients with scrub typhus or an assessment of diagnostic $\mathrm{Ab}$ cutoff values have rarely been performed [4].

In the present study, we conducted a follow-up investigation to examine $\mathrm{Ab}$ titers in patients with scrub typhus using IFA, which were used by the Korea Centers for Disease Control and Prevention (KCDC), and serologic tests, which were used by various commercial laboratories.

\section{Methods}

This study included adults aged $\geq 18$ years who had a history of fever within the past month, those who visited Chosun University Hospital between May 2016 and May 2018, and those who were diagnosed with scrub typhus. Ab titers were prospectively assayed every 7 days for 1 month after treatment and every 6 months for 18 months thereafter. The diagnostic criteria for scrub typhus were a $\geq 4$-fold increase in levels of IgM or IgG Ab titers against $O$. tsutsugamushi in the IFA or positive results of nested polymerase chain reaction (PCR) targeting O. tsutsugamushi-specific $56-\mathrm{kDa}$ gene or $16 \mathrm{~S}$ rRNA gene $[5,6]$. In addition, patients were examined for diseases similar to scrub typhus, including murine typhus, leptospirosis, hemorrhagic fever with renal syndrome, and systemic lupus erythematosus. Patients with evidence of these diseases were excluded to eliminate their potential confounding effects on the clinical manifestations and test results [1]. In addition to the prospective investigation, patients who were admitted to Chosun University Hospital and diagnosed with scrub typhus between 2004 and 2016 were contacted individually; those who provided consent underwent follow-up titer investigations. Serum samples were also obtained from individuals who underwent blood tests as part of the health checkup performed in the hospital during the study period.

Diagnostic tests using the KCDC method and Ab tests from various commercial laboratories were performed simultaneously. The indirect IFA used by the KCDC detects serum IgM and IgG in patients who respond to mixed O. tsutsugamushi antigens-Gilliam, Karp, Kato, and Boryoung-as described previously [4]. To perform IFA according to the KCDC method, two-fold serial dilutions from 1:16 human sera were reacted with mixed O. tsutsugamushi antigens. The IFA positive cutoff value for scrub typhus used by the KCDC was $\geq 1: 16$ for IgM and $\geq 1: 256$ for IgG.

The IFA for detecting total Ig was performed at a company in South Korea (designated as "A"), which is a commercial laboratory. This IFA measures the total $\mathrm{Ab}$ (IgM/IgG/IgA) against O. tsutsugamushi (Boryoung, Karp, and Gilliam antigens). Two-fold serial dilutions from 1:40 human sera were reacted with mixed $O$. $t s u$ tsugamushi antigens for $\mathrm{Ab}$ tests to detect total Ig by company A. The IFA positive cutoff value for scrub typhus used by company A was $\geq 1: 40$ for total Ig.

Immunochromatography was performed in the our hospital laboratory using two commercially available kits from companies designated as "C" and "D" in South Korea in accordance with manufacturers' instructions. The commercial kit of company $\mathrm{C}$ is a diagnostic immunochromatography kit that uses a mixed antigen consisting of the $56-\mathrm{kDa}$ protein of O. tsutsugamushi Kangwon and 21-kDa protein of O. tsutsugamushi Boryoung [7, 8]. The commercial kit of company D measures the total Ab (IgM/IgG/IgA) in serum samples using O. tsutsugamushi Gilliam, Karp, and Kato antigens [7].

\section{Results}

Of the 321 patients suspected of having infections related to outdoor activities between May 2016 and May 2018, 158 were suspected to have scrub typhus; 102 patients were confirmed to have O. tsutsugamushi infection (Supplementary Table 1). We followed up these patients by investigating their Ab titers. In total, 101 samples from 102 patients were sent to company A for $\mathrm{Ab}$ tests to detect the total Ig. The IgM titer values remained at peak for 2-5 weeks after symptom onset and subsequently decreased. Similarly, the IgG Ab titer 


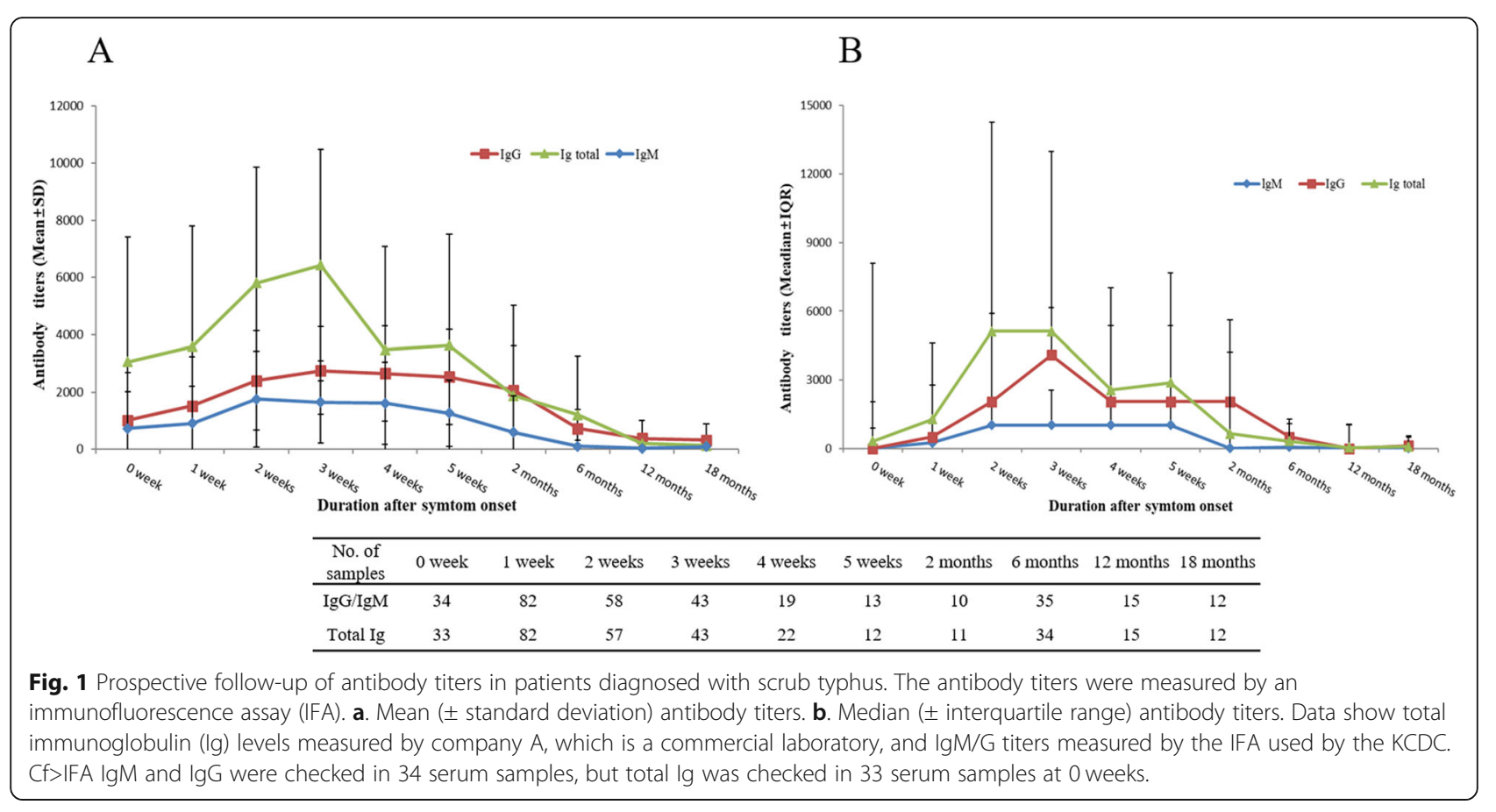

values also rapidly increased 1-3 weeks after symptom onset, reached a peak at around 3-4 weeks, subsequently decreased and remained stable for 2 months, and finally declined slowly (Fig. 1). The total Ig Ab titer values rapidly increased around 1 week after symptom onset, reached a peak at 2-3 weeks, and subsequently declined (Supplementary Table 2). The Ab positivity rates within 5 days of symptom onset ( 0 week) were $44.1,35.3$, and $57.6 \%$ for cutoff values of $\geq 1: 16$ for IgM, $\geq 1: 256$ for IgG, and $\geq 1: 40$ for total Ig, respectively. The Ab positive rates were $68.3,61.0$, and $84.1 \%$, respectively, within 6-10 days of symptom onset (1 week) (Supplementary Tables 1 and 2).The commercial kit of company $C$ was used to investigate the serum samples of 35 patients who were followed up for approximately 6 months. Of the 35 patients, 11 were positive for IgM, corresponding to a positivity rate of $31.4 \%$, and six were positive for IgG, corresponding to a positivity rate of $17.1 \%$. When the commercial kit of company D was used, 23 of 35 patients showed positive results, corresponding to a positivity rate of $65.7 \%$ at approximately 6 months. None of the patients who were followed up for 18 months were positive for IgM; however, one patient was positive for IgG using the commercial kit of company C. Eight of 12 patients showed positive results, corresponding to a positivity rate of $66.7 \%$ at 18 months (Table 1 ) using the commercial kit of company D. A follow-up study regarding $\mathrm{Ab}$ titers was performed in healthy individuals who had recovered from scrub typhus. Overall, 636 patients were admitted to Chosun University Hospital for scrub typhus and were diagnosed positive for O. tsutsugamushi using PCR. Of these, the Ab titers of 91 individuals were followed up for $\geq 1$ year and up to a maximum of 13 years after recovery; 34 (37.4\%) had IgM titers $\geq 1: 16$. Of the 52 individuals who had recovered from scrub typhus in the past 5 years, 27 (51.9\%) had IgM titers $\geq 1: 16$. Of the 28 individuals who were followed up for $\geq 6$ years and up to 10 years, four (14.3\%) had IgM titers $\geq 1: 16$. Of the 17 individuals who had recovered for $>10$ years, three $(17.6 \%)$ had IgM titers $\geq 1: 16$. In a 1 -year period,

Table 1 Prospective follow-up of antibody titers in patients with scrub typhus using rapid diagnostic test using immunochromatography performed using commercial kits from companies C and D

\begin{tabular}{|c|c|c|c|c|c|c|c|c|c|}
\hline & \multicolumn{3}{|l|}{6 Months } & \multicolumn{3}{|l|}{12 Months } & \multicolumn{3}{|l|}{18 Months } \\
\hline & \multicolumn{2}{|c|}{ C company kit } & \multirow{2}{*}{$\begin{array}{l}\text { D company kit } \\
n(C P)\end{array}$} & \multicolumn{2}{|c|}{ C company kit } & \multirow{2}{*}{$\begin{array}{l}\text { D company kit } \\
n(\mathrm{CP})\end{array}$} & \multicolumn{2}{|c|}{ C company kit } & \multirow{2}{*}{$\begin{array}{l}\text { D company kit } \\
n(\mathrm{CP})\end{array}$} \\
\hline & $\lg M n(C P)$ & $\lg \boldsymbol{n}(\mathrm{CP})$ & & $\lg M n(C P)$ & $\lg n n(C P)$ & & $\lg M n(C P)$ & $\lg G n(C P)$ & \\
\hline Negative $n$ & $24(68.6)$ & $29(82.9)$ & $12(34.3)$ & $16(100)$ & $16(100)$ & $2(12.5)$ & $12(100)$ & $11(91.7)$ & $4(33.3)$ \\
\hline Positive $n$ & $11(31.4)$ & $6(17.1)$ & $23(65.7)$ & $0(\mathbf{0})$ & $0(\mathbf{0})$ & $14(87.5)$ & $0(0)$ & $1(8.3)$ & $8(66.7)$ \\
\hline Total $n$ & 35 & 35 & 35 & 16 & 16 & 16 & 12 & 12 & 12 \\
\hline
\end{tabular}

CP Cumulative percentage 


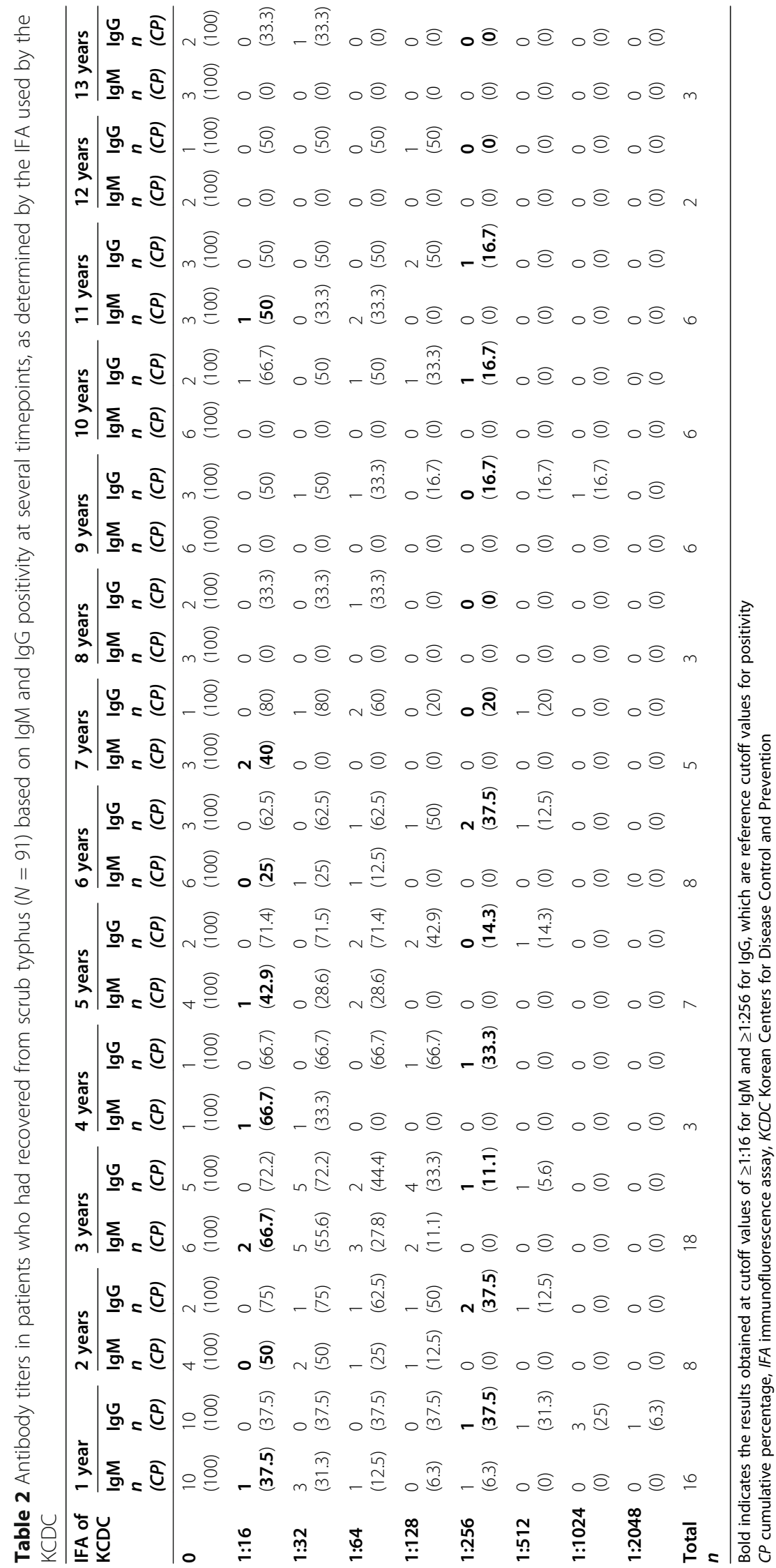


Table 3 Antibody titers in patients who had recovered from scrub typhus $(N=91)$ based on positive rates of the total antibody titer, as determined by the IFA used by company $A$

\begin{tabular}{|c|c|c|c|c|c|c|c|c|c|c|c|c|c|}
\hline $\begin{array}{l}\text { IFA of A } \\
\text { Company }\end{array}$ & $\begin{array}{l}1 \text { year } \\
\mathrm{n}(\mathrm{CP})\end{array}$ & $\begin{array}{l}2 \text { years } \\
n(\mathrm{CP})\end{array}$ & $\begin{array}{l}3 \text { years } \\
n(C P)\end{array}$ & $\begin{array}{l}4 \text { years } \\
n(C P\end{array}$ & $\begin{array}{l}5 \text { years } \\
\mathrm{n}(\mathrm{CP})\end{array}$ & $\begin{array}{l}6 \text { years } \\
n(C P)\end{array}$ & $\begin{array}{l}7 \text { years } \\
n(C P)\end{array}$ & $\begin{array}{l}8 \text { years } \\
n(C P\end{array}$ & $\begin{array}{l}9 \text { years } \\
\mathrm{n}(\mathrm{CP})\end{array}$ & $\begin{array}{l}10 \text { years } \\
\mathrm{n}(\mathrm{CP})\end{array}$ & $\begin{array}{l}11 \text { years } \\
n(C P)\end{array}$ & $\begin{array}{l}12 \text { years } \\
n(\mathrm{CP})\end{array}$ & $\begin{array}{l}13 \text { years } \\
\mathrm{n}(\mathrm{CP})\end{array}$ \\
\hline 0 & $6(100)$ & $0(100)$ & $2(100)$ & $1(100)$ & $1(100)$ & $1(100)$ & $1(100)$ & $1(100)$ & $1(100)$ & $1(100)$ & $3(100)$ & $2(100)$ & $1(100)$ \\
\hline $1: 40$ & $3(62.5)$ & $0(100)$ & $8(88.9)$ & $0(66.7)$ & $1(85.7)$ & $4(87.5)$ & $2(80)$ & $1(66.7)$ & $4(83.3)$ & $1(83.3)$ & $0(50)$ & $0(0)$ & $2(66.7)$ \\
\hline $1: 80$ & $1(43.8)$ & $0(100)$ & $1(44.4)$ & $0(66.7)$ & $3(71.4)$ & $0(37.5)$ & $1(40)$ & $1(33.3)$ & $0(16.6)$ & $1(66.7)$ & $3(50)$ & $0(0)$ & $0(0)$ \\
\hline 1:160 & $1(37.5)$ & $2(100)$ & $4(38.9)$ & $1(66.7)$ & $2(28.6)$ & $3(37.5)$ & $1(20)$ & $0(0)$ & $0(16.6)$ & $3(50.0)$ & $0(0)$ & $0(0)$ & $0(0)$ \\
\hline $1: 320$ & $2(31.3)$ & $2(75.0)$ & $0(16.7)$ & $1(33.3)$ & $0(0)$ & $0(0)$ & $0(0)$ & $0(0)$ & $0(16.6)$ & $0(0)$ & $0(0)$ & $0(0)$ & $0(0)$ \\
\hline 1:640 & $2(18.8)$ & $4(50.0)$ & $3(16.7)$ & $0(0)$ & $0(0)$ & $0(0)$ & $0(0)$ & $0(0)$ & $0(16.6)$ & $0(0)$ & $0(0)$ & $0(0)$ & $0(0)$ \\
\hline $1: 1280$ & $1(6.3)$ & $0(0)$ & $0(0)$ & $0(0)$ & $0(0)$ & $0(0)$ & $0(0)$ & $0(0)$ & $0(16.6)$ & $0(0)$ & $0(0)$ & $0(0)$ & $0(0)$ \\
\hline $1: 2560$ & $0(0)$ & $0(0)$ & $0(0)$ & $0(0)$ & $0(0)$ & $0(0)$ & $0(0)$ & $0(0)$ & $0(16.6)$ & $0(0)$ & $0(0)$ & $0(0)$ & $0(0)$ \\
\hline $1: 5120$ & $0(0)$ & $0(0)$ & $0(0)$ & $0(0)$ & $0(0)$ & $0(0)$ & $0(0)$ & $0(0)$ & $1(16.6)$ & $0(0)$ & $0(0)$ & $0(0)$ & $0(0)$ \\
\hline$>1: 5120$ & $0(0)$ & $0(0)$ & $0(0)$ & $0(0)$ & $0(0)$ & $0(0)$ & $0(0)$ & $0(0)$ & $0(0)$ & $0(0)$ & $0(0)$ & $0(0)$ & $0(0)$ \\
\hline Total $\mathbf{n}$ & 16 & 8 & 18 & 3 & 7 & 8 & 5 & 3 & 6 & 6 & 6 & 2 & 3 \\
\hline
\end{tabular}

Bold indicates the results obtained at cutoff values of $\geq 1: 40$ for total Ig detection, which are reference cutoff values for positivity

$C P$ Cumulative percentage, IFA Immunofluorescence assay

one of 16 individuals with a IgM cutoff titer $\geq 1: 128$ had positive test results, corresponding to a positivity rate of $6.3 \%$. None of the individuals had IgM titers $\geq 1: 128$ after 4 years. During the total follow-up period, 20 of the 91 $(22.0 \%)$ individuals had IgG cutoff titers $\geq 1: 256$. IgG titers $\geq 1: 256$ were observed in 13 (25.0\%) of 52 individuals who had recovered from scrub typhus in the last 5 years and six $(21.4 \%)$ of 28 individuals who were followed up for $\geq 6$ and up to 10 years. Of the 17 individuals who had recovered for $>10$ years, two (11.8\%) had IgG titers $\geq 1: 256$. Five of 91 individuals had IgG titers $\geq 1: 1024$, corresponding to a positivity rate of $5.5 \%$ (Table 2). Of the 91 patients for whom a total Ig titer values were investigated using the commercial kit of company A, 70 (76.9\%) had total Ig titers $\geq 1: 40$ (Table 3 ). When the commercial kits of company $\mathrm{C}$ were used in 91 individuals who had recovered from scrub typhus, the samples were negative for IgM. Five (5.5\%) of 91 individuals who were followed up for 13 years showed positive results for IgG. When the commercial kits of company D were used, 42 (46.2\%) of 91 individuals whose $\mathrm{Ab}$ titers were followed up for 13 years showed a positive result (Table 4). To investigate seroprevalence, IFA was performed using samples from 216 individuals who underwent health checkups. When the cutoff value was set to $\geq 1: 16$ for IgM titers, $4.2 \%$ (9/216) individuals showed IgM seropositivity. However, when the cutoff value was set to 1:256 for IgG, seropositivity was absent (Table 5, Fig. 2). When the commercial kits of the companies $C$ and $D$ were used for samples from the 216 health checkup recipients, one patient showed positive results and the remaining 215 showed negative results using the commercial kits of company D; however, all 216 individuals were negative for IgM and IgG using the commercial kits of company C (data not shown).

\section{Discussion}

This prospective study to assess the antibody titers in 102 patients with scrub typhus showed that the antibody positivity rates within 5 days of symptom onset were $44.1,35.3$, and $57.6 \%$ when cutoff values were used $\geq 1$ : 16 for IgM, $\geq 1: 256$ for IgG, and $\geq 1: 40$ for total Ig, respectively. The IgM, IgG, and total Ig positivity rates for 13 years in the follow-up investigations with 91 individuals who recovered from scrub typhus were 37.4, 22.0, and $76.9 \%$, respectively.

A limitation of serological tests for the diagnosis of scrub typhus is the insufficient formation of antibodies in the early or acute phases of infection, which could lead to false-negative results. To set an appropriate cutoff for the region and for accurate diagnosis, it is necessary to have information regarding seroprevalence, $\mathrm{Ab}$ titers in the endemic region, and $\mathrm{Ab}$ titers maintained in patients who have recovered from scrub typhus. Otherwise, falsepositive results may be obtained. Moreover, in an endemic situation, using $\mathrm{Ab}$ tests to detect total Ig may lead to more frequent false-positive results as a consequence of IgG remaining from a previous infection [8].

According to a study by Blacksell on the usefulness of the indirect immunofluorescence method, which is the gold standard for diagnosis of scrub typhus [9], the cutoff value used in Thailand and Malaysia (range, 1:50-1: 400) differs from that used in Japan and South Korea (range, 1:10-1:40). The most commonly used single titer cutoff value was 1:400. Many countries, including Thailand and Malaysia, use a cutoff value as high as 1 : 400. In this prospective study, most subjects (14/15, 93.3\%) underwent negative seroconversion within 1 year when a cutoff value $\geq 1: 128$ was used. However, lower cutoff values (1:10-1:40), such as those used in Korea 
Table 4 Antibody titers in patients who had recovered from scrub typhus ( $N=91$ ) based on follow-up at several timepoints using commercial kits from companies $C$ and $D$

\begin{tabular}{|c|c|c|c|c|c|}
\hline & Company & Antibody & $\begin{array}{l}\text { Negative } \\
n\end{array}$ & $\begin{array}{l}\text { Positive } \\
n\end{array}$ & $\begin{array}{l}\text { Total } \\
n\end{array}$ \\
\hline \multirow[t]{3}{*}{1 year } & $C$ & $\lg M$ & 16 & 0 & 16 \\
\hline & & $\lg G$ & 16 & 0 & \\
\hline & $\mathrm{D}$ & & 2 & 14 & \\
\hline \multirow[t]{3}{*}{2 years } & $C$ & $\lg M$ & 8 & 0 & 8 \\
\hline & & $\lg G$ & 7 & 1 & \\
\hline & $D$ & & 2 & 6 & \\
\hline \multirow[t]{3}{*}{3 years } & $C$ & $\lg M$ & 18 & 0 & 18 \\
\hline & & $\lg G$ & 18 & 0 & \\
\hline & $\mathrm{D}$ & & 10 & 8 & \\
\hline \multirow[t]{3}{*}{4 years } & $C$ & $\lg M$ & 3 & 0 & 3 \\
\hline & & $\lg G$ & 3 & 0 & \\
\hline & $\mathrm{D}$ & & 2 & 1 & \\
\hline \multirow[t]{3}{*}{5 years } & $C$ & $\lg M$ & 7 & 0 & 7 \\
\hline & & $\lg G$ & 7 & 0 & \\
\hline & $\mathrm{D}$ & & 3 & 4 & \\
\hline \multirow[t]{3}{*}{6 years } & $C$ & $\lg M$ & 8 & 0 & 8 \\
\hline & & $\lg G$ & 8 & 0 & \\
\hline & $D$ & & 7 & 1 & \\
\hline \multirow[t]{3}{*}{7 years } & $C$ & $\lg M$ & 5 & 0 & 5 \\
\hline & & $\lg G$ & 5 & 0 & \\
\hline & $D$ & & 5 & 0 & \\
\hline \multirow[t]{3}{*}{8 years } & $C$ & $\lg M$ & 3 & 0 & 3 \\
\hline & & $\lg G$ & 3 & 0 & \\
\hline & $\mathrm{D}$ & & 3 & 0 & \\
\hline \multirow[t]{3}{*}{9 years } & $C$ & $\lg M$ & 6 & 0 & 6 \\
\hline & & $\lg G$ & 2 & 4 & \\
\hline & $\mathrm{D}$ & & 3 & 3 & \\
\hline \multirow[t]{3}{*}{10 years } & $C$ & $\lg M$ & 6 & 0 & 6 \\
\hline & & $\lg G$ & 6 & 0 & \\
\hline & $\mathrm{D}$ & & 6 & 0 & \\
\hline \multirow[t]{3}{*}{11 years } & $C$ & $\lg M$ & 6 & 0 & 6 \\
\hline & & $\lg G$ & 6 & 0 & \\
\hline & $\mathrm{D}$ & & 3 & 3 & \\
\hline \multirow[t]{3}{*}{12 years } & $C$ & $\lg M$ & 2 & 0 & 2 \\
\hline & & $\lg G$ & 2 & 0 & \\
\hline & $\mathrm{D}$ & & 1 & 1 & \\
\hline \multirow[t]{3}{*}{13 years } & $C$ & $\lg M$ & 3 & 0 & 3 \\
\hline & & $\lg G$ & 3 & 0 & \\
\hline & D & & 2 & 1 & \\
\hline
\end{tabular}

C, C company kit; D, D company kit
Table $\mathbf{5} \mathrm{lgM} / \mathrm{G}$ positivity determined by the IFA used by the KCDC in individuals undergoing health checkup

\begin{tabular}{lll}
\hline & IgM & IgG \\
& $\boldsymbol{n}(\boldsymbol{C P})$ & $\boldsymbol{n}(\boldsymbol{C P})$ \\
\hline 0 & $207(100)$ & $179(100)$ \\
$1: 16$ & $9(4.2)$ & $16(17.1)$ \\
$1: 32$ & $0(0)$ & $15(9.7)$ \\
$1: 64$ & $0(0)$ & $3(2.8)$ \\
$1: 128$ & $0(0)$ & $3(1.4)$ \\
Total & 216 & 216 \\
\hline CP Cumulative percentage, IFA Immunofluorescence assay, KCDC Korean \\
Centers for Disease Control and Prevention
\end{tabular}

and Japan, resulted in six of 16 patients showing positive result at 1 year (37.5\%) when the IgM value was set at 1 : 16 in our study.

To accurately diagnose scrub typhus, negative diagnostic test results need to be observed in patients who have recovered from past scrub typhus. Therefore, it is important to know how long Ab levels are maintained in patients who have recovered. Moreover, to evaluate the accuracy of the various IFAs, which are employed in commercial laboratories, patients who have recovered from scrub typhus should be studied, and the falsepositive results in this population should be determined for each assay kit.

The KCDC's criteria for scrub typhus reporting and diagnosis are cutoff values $\geq 1: 16$ for IgM and $\geq 1: 256$ for IgG. In this study, Ab titers were evaluated in 91 individuals who had recovered from scrub typhus and were followed up for a maximum of 13 years. In the IFA used by company A to measure total Ig for 13 years, $76.9 \%$ individuals showed a positive result. Using the commercial kits of company D, $46.2 \%$ individuals showed a positive result within 13 years. When IgM and IgG cutoff values ( $\geq 1: 16$ and $\geq 1: 256$, respectively) used in the KCDC's IFA were applied within 13 years, 37.3 and $22.0 \%$, respectively, patients showed positive results. These results show that IFAs and commercial kits of company D are highly likely to misdiagnose diseases other than scrub typhus as patients who previously had scrub typhus showed positive results due to the presence of lingering residual Abs.

We also evaluated the test results of 91 healthy individuals who had recovered from scrub typhus and who were followed up for 13 years to set the IFA IgM cutoff. When the IgM cutoff was set to $1: 128$, four $(4.4 \%)$ of 91 individuals showed a positive result when the test was conducted within 13 years and four (5\%) of 80 individuals showed a positive result when the test was conducted within 10 years. None of the individuals showed a positive result after 10 years. When the IgG cutoff was set to $1: 1024$ in the IFA, five (5.5\%) of 91 individuals 


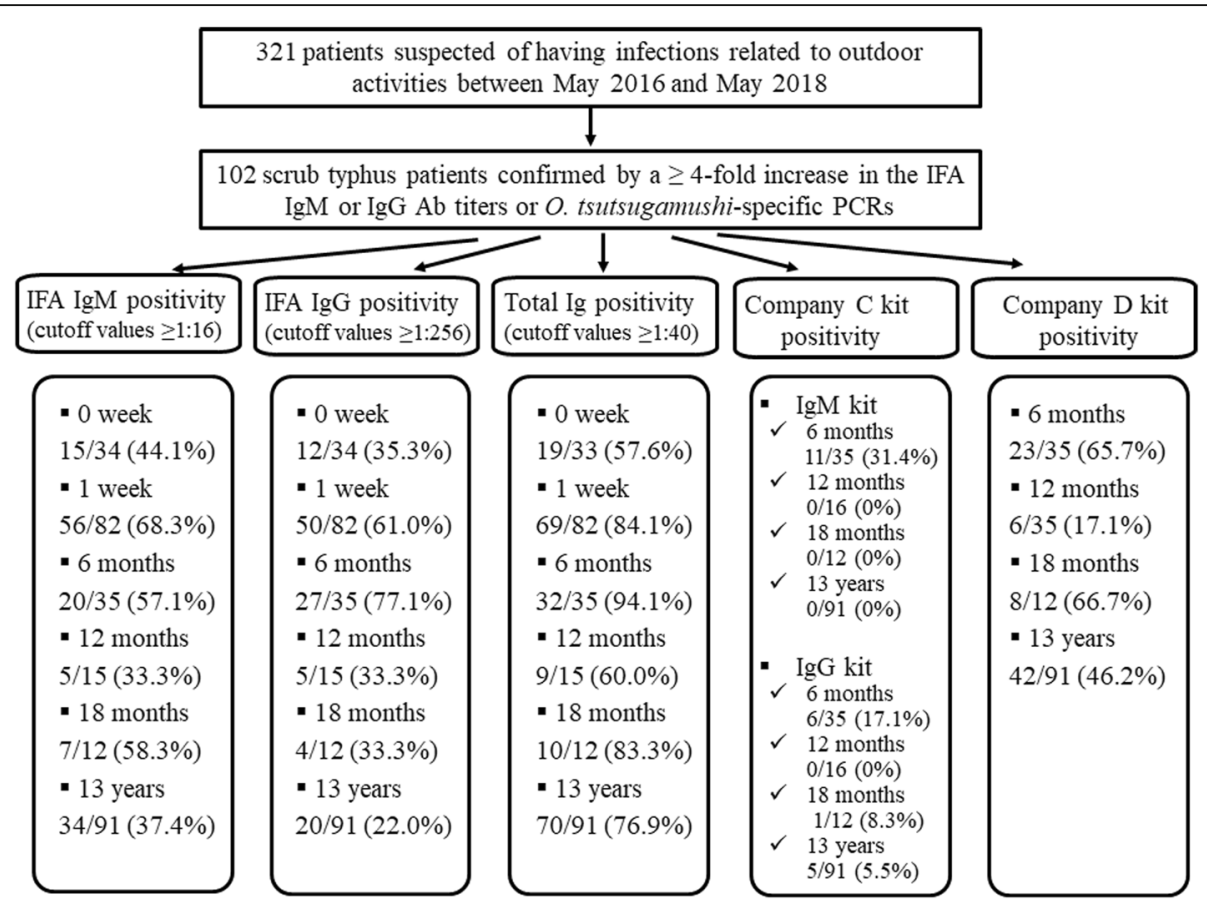

Fig. 2 Overview of prospective and retrospective follow-up antibody titers determined by the following tests: (i) IFA used by KCDC to detect IgM and IgG, (ii) IFA used by company A to detect total Ig, and (iii) antibody tests using two commercially available kits from companies $C$ and $D$

showed a positive result within 13 years and six (7.5\%) of 80 individuals showed a positive result within 10 years. None of the individuals showed a positive result after 10 years. Therefore, to distinguish patients with previous infection from those with current infection, an upward adjustment of cutoff values is needed, including those for IFAs performed by the KCDC and company A.

Since there are statistically significant differences in the seroprevalence of scrub typhus across geographical regions, studies on the baseline seroprevalence in each region are important to determine a diagnostic cutoff value for scrub typhus [10]. An Ab titer analysis was performed among healthy individuals who underwent blood tests as part of a health checkup in a university hospital. This analysis showed that the IgM seropositivity rate was $4.2 \%(9 / 216)$ for a cutoff value of $\geq 1: 16$ and the IgG seropositivity was absent for a cutoff value of 1:256. Therefore, an IgM cutoff value of 1:16 meant that $4.2 \%$ healthy individuals are likely to be misdiagnosed with scrub typhus; thus, an upward adjustment of the IgM titer is necessary.

The limitation of this study is that the data were obtained from patients who visited a single university hospital in Gwangju for medical examination; they do not reflect the background Ab titer of the entire country. The national seroprevalence and background $\mathrm{Ab}$ titers must be considered when determining the cutoff value for diagnosing scrub typhus. In addition to considerations regarding $\mathrm{Ab}$ titer longevity in previously infected patients, data on $\mathrm{Ab}$ cross-reactions in patients with other acute infections must also be reviewed to determine the cutoff value. Thus, prospective studies on crossreactions and diagnostic accuracy are needed to determine an appropriate cutoff value for each country. Another limitation of this study is that all samples from patients with scrub typhus who visited the hospital were collected periodically and then frozen at $-20{ }^{\circ} \mathrm{C}$. We performed diagnostic tests to assess the antibody titers for scrub typhus at the same time or at a similar time.

\section{Conclusion}

In conclusion, this study shows that the commercial kits commonly used in clinical settings in South Korea and IFA used by the KCDC could not distinguish patients who had recovered from scrub typhus from those who currently have scrub typhus. In South Korea and other countries, where cutoff values for titers are used as the criteria for reporting and diagnosing scrub typhus, an upward adjustment of the cutoff values may be necessary. To determine an appropriate cutoff value, prospective studies on background $\mathrm{Ab}$ titers are needed at a national level. 


\section{Supplementary Information}

The online version contains supplementary material available at https://doi. org/10.1186/s12879-020-05735-8.

Additional file 1: Table S1. Prospective follow-up of antibody titers in patients with scrub typhus ( $N=102)$ based on IgM/G antibody titers determined by the IFA method used by the KCDC. Table S2. Prospective follow-up of antibody titers in patients with scrub typhus $(\mathrm{N}=101)$ based on total lgG antibody titers determined by the IFA used by company A (a commercial laboratory).

\section{Abbreviations}

KCDC: Korea Centers for Disease Control and Prevention:

IFA: Immunofluorescence antibody assay; Ab: Antibody; Ig: Immunoglobulin; PCR: Polymerase chain reaction

\section{Acknowledgements}

We presented a poster in IDWeek 2019 (poster no. 2138) using some of the content before submitting to BMC Infectious Diseases.

\section{Authors' contributions}

CMK designed the study; participated in data collection, laboratory analysis such as molecular analysis and serological testing; wrote the original manuscript; and revised the draft during the submission process. DMK designed and coordinated the study and contributed to drafting and reviewing the manuscript during the course of submission. NRY participated in serological testing, contributed to clinical evaluation, and revised the manuscript. All the authors have read and approved the final version of the manuscript.

\section{Funding}

This study was supported by research grants (2016-E52003-00, 2016-E5200301) from the Korea Centers for Disease Control and Prevention (KCDC). Fund was utilized in research planning, design, laboratory analysis, clinical evaluation, and work force cost.

\section{Availability of data and materials}

The datasets used and/or analysed during the current study are available from the corresponding author on reasonable request.

\section{Ethics approval and consent to participate}

The study was approved by the Ethics in Human Research Committee of Chosun University Hospital (IRB No. 2013-10-001, IRB No. 2016-07-014). The adult human subjects provided written informed consent to participate in the study.

\section{Consent for publication}

Not applicable.

\section{Competing interests}

The authors do not have any commercial interests or other associations that might pose a conflict of interest.

\section{Author details}

'Premedical Science, College of Medicine, Chosun University, Gwangju, Republic of Korea. ${ }^{2}$ Departments of Internal Medicine, College of Medicine, Chosun University, Gwangju, Republic of Korea.

Received: 1 September 2020 Accepted: 22 December 2020 Published online: 13 January 2021

\section{References}

1. Kim YS, Kim DM, Yoon NR, Jang MS, Kim CM. Effects of rifampin and doxycycline treatments in patients with uncomplicated scrub typhus: an open-label, randomized, controlled trial. Clin Infect Dis. 2018:67(4):600-5.

2. Gupta N, Chaudhry R, Thakur CK. Determination of cutoff of ELISA and Immunofluorescence assay for scrub typhus. J Global Infect Dis. 2016;8(3): 97-9.
3. Lim C, Blacksell SD, Laongnualpanich A, Kantipong P, Day NP, Paris DH, et al. Optimal cutoff titers for indirect immunofluorescence assay for diagnosis of scrub typhus. J Clin Microbiol. 2015;53(11):3663-6.

4. Kim DM, Lee YM, Back JH, Yang TY, Lee JH, Song HJ, et al. A serosurvey of Orientia tsutsugamushi from patients with scrub typhus. Clin Microbiol Infect. 2010;16(5):447-51.

5. Kim CM, Cho MK, Kim DM, Yun NR, Kim SW, Jang SJ, et al. Accuracy of conventional PCR targeting the 16S rRNA gene with the Ot-16sRF1 and Ot16sRR1 primers for diagnosis of scrub typhus: a case-control study. J Clin Microbiol. 2016;54(1):178-9.

6. Lee YM, Kim DM, Lee SH, Jang MS, Neupane GP. Phylogenetic analysis of the $56 \mathrm{kDa}$ protein genes of Orientia tsutsugamushi in southwest area of Korea. Am J Trop Med Hyg. 2011;84(2):250-4.

7. Kim YJ, Park S, Premaratna R, Selvaraj S, Park SJ, Kim S, et al. Clinical evaluation of rapid diagnostic test kit for scrub typhus with improved performance. J Korean Med Sci. 2016;31(8):1190-6.

8. Lee KD, Moon C, Oh WS, Sohn KM, Kim BN. Diagnosis of scrub typhus: introduction of the immunochromatographic test in Korea. Korean J Intern Med. 2014;29(2):253-5.

9. Blacksell SD, Bryant NJ, Paris DH, Doust JA, Sakoda Y, Day NPJ. Scrub typhus serologic testing with the indirect immunofluorescence method as a diagnostic gold standard: a lack of consensus leads to a lot of confusion. Clin Infect Dis. 2007:44(3):391-401.

10. Jakharia A, Borkakoty B, Biswas D, Yadav K, Mahanta J. Seroprevalence of scrub typhus infection in Arunachal Pradesh, India. Vector Borne Zoonotic Dis. 2016;16(10):659-63.

\section{Publisher's Note}

Springer Nature remains neutral with regard to jurisdictional claims in published maps and institutional affiliations.

\section{Ready to submit your research? Choose BMC and benefit from:}

- fast, convenient online submission

- thorough peer review by experienced researchers in your field

- rapid publication on acceptance

- support for research data, including large and complex data types

- gold Open Access which fosters wider collaboration and increased citations

- maximum visibility for your research: over $100 \mathrm{M}$ website views per year

At $\mathrm{BMC}$, research is always in progress.

Learn more biomedcentral.com/submissions 